\title{
RINONEUMONITIS EQUINA EN CABALLOS DEL VALLE DE LIMA
}

\author{
Paolo Ríos S. ${ }^{1}$, Alfredo Benito Z. ${ }^{2}$ y Hermelinda Rivera G. ${ }^{2,3}$
}

\section{Abstract}

The objective of this study was to determine the prevalence of the equine herpes virus type 1 (EHV-1), the causative agent of equine rhinopneumonitis, in mature healthy horses of various breeds reared in Lima valley, Peru. For this purpose serum samples $(n=448)$ were collected during October 2000 till March 2001 for detecting neutralizing antibodies against EHV-1 by virus neutralisation test. The prevalence of EHV- 1 was $44.2 \pm 4.6 \%$. The highest prevalence was detected in Standardbred (52.6\%) followed by Thoroughbred (47.1\%) and Peruvian horses de Paso (34.8\%). Antibody titres against EHV-1 ranged between 2 to $>256$. There was no statistical association between the presence of antibodies against EHV-1, sex, activity and location of the horses. This results indicate that the EHV-1 has wide distribution in horses reared in the Lima valley, Perú.

Key words: horses equine rhinopneumonitis, equine herpes virus type 1, antibodies, virus neutralization test

\section{Resumen}

El objetivo del presente estudio fue determinar la prevalencia del virus herpes equino tipo 1 (VHE-1), agente causal de la rinoneumonitis equina, en caballos adultos aparentemente normales dedicados a diferentes actividades, y criados en el valle de Lima. Con este fin se colectaron muestras de suero $(n=448)$ entre octubre del 2000 a marzo del 2001 para detectar anticuerpos neutralizantes contra el VHE-1 mediante la prueba de neutralización viral. La prevalencia del VHE-1 en las muestras estudiadas fue de $44.2 \pm 4.6 \%$. La mayor prevalencia fue detectada en caballos de equitación (52.6\%) seguido por caballos de carrera $(47.1 \%$ ) y caballos peruanos de paso (34.8\%). Los títulos de anticuerpos contra el virus estuvieron entre 2 a $>256$. No se encontró asociación estadística significativa entre la presencia de anticuerpos con las variables, sexo, actividad y procedencia de los caballos. Los resultados indican que el VHE-1 está ampliamente distribuido en la población de equinos criados en el valle de Lima.

Palabras clave: caballos, rinoneumonitis equina, virus herpes equino tipo 1, anticuerpos, neutralización viral

\footnotetext{
${ }^{\prime}$ Práctica privada

${ }^{2}$ Laboratorio de Microbiología y Parasitología, FMV-UNMSM

${ }^{3}$ E-mail: hriverag@vet.unmsm.edu.pe
} 


\section{INTRODUCCIÓN}

La rinoneumonitis equina ( $R N E$ ) es un término colectivo que involucra a dos patologías de origen viral que afectan a los caballos domésticos (Equus caballus) de todas las edades y razas a nivel mundial (OIE, 2000). La RNE es producida por dos agentes virales inmunológicamente relacionados aunque molecularmente diferentes. El virus herpes equino de tipo 1 (VHE 1), principal causante de abortos, problemas respiratorios, neurológicos y mortalidad perinatal; y el virus herpes equino de tipo 4 (VHE 4), que es el principal agente primario de procesos respiratorios caracterizados por rinofaringitis, traqueobronquitis y ocasionalmente causante de abortos (Ellis et al., 1995).

Estos virus ocasionan significantes pérdidas económicas en lugares donde la RNE es enzoótica como EE.UU., Inglaterra y España, o en países donde la población equina constituye un rubro importante de su economía (OIE, 2000).

La principal forma de transmisión del VHE-1 y VHE-4 es por inhalación de aerosoles a partir de secreciones respiratorias de caballos con la enfermedad respiratoria, o por contacto con el feto abortado, membranas fetales o residuos de fluidos fetales infectados con los virus. Además, el VHE-1 y VHE-4 persisten en la naturaleza a través de las infecciones latentes; a partirde las cuales los virus se reactivan y se diseminan periódicamente a otros caballos susceptibles (Van der Meulen et al., 2000). En el Perú la RNE fue reportada durante un brote de abortos en caballos de carrera (Rivera $e t$ al., 1975), y más recientemente durante otro brote de abortos ocurridos en un criadero al norte de Lima (Rivera et al., 1997).

Muchos de los problemas respiratorios que ocurren en los potrillos y potros, así como los abortos esporádicos pueden ser debidos a los virus causantes de la RNE (Rivera $\mathrm{H}$., comunicación personal). A pesar de la importancia de esta enfermedad, se dispone de escasa información sobre su situación epidemiológica en nuestro medio, lo que motivó la realización del presente estudio que tuvo por objetivo determinar la frecuencia de VHE-1 en caballos procedentes de 5 lugares de Lima.

\section{Materialas y Métodos}

\section{Muestras de Suero}

Se utilizaron 448 muestras de suero de equinos de ambos sexos mayores a 6 meses de edad. Las muestras pertenecían al banco de sueros de caballos existentes en el Laboratorio de Virología de la Facultad de Medicina Veterinaria (FMV) de la Universidad Nacional Mayor de San Marcos (UNMSM) obtenidas entre octubre del 2000 a marzo del 2001. Las muestras fueron obtenidas de caballos del Hipódromo de Surco, de la Escuela de Caballería del Ejército Peruano de Chorrillos, y de tres criaderos de Caballos Peruanos de Paso ubicados en los distritos de Cieneguilla, Lurín y Pachacamac.

\section{Detección de Anticuerpos}

Los anticuerpos fueron detectados mediante la prueba de neutralización viral siguiendo el método de microtitulación en placas descartables de 96 huecos, según el protocolo disponible en el Laboratorio de Virología de la FMV, UNMSM. Como sistema indicador de esta prueba se utilizaron células de cornete nasal de feto bovino preparados de acuerdo al protocolo desarrollado por el laboratorio de virología de la FMV, UNMSM.

Como antígeno se empleó la cepa vacunal Rhinomune EHV-1 obtenida comercialmente de EE.UU., adaptada a células de cornete nasal bovino, con un título de $10^{4.75}$ $\mathrm{DI}_{50} \mathrm{c} / 50 \mu \mathrm{l}$.

\section{Análisis de Datos}

Se determinó la prevalencia (P) del VHE-1 mediante la relación porcentual en- 
tre el número de animales que presentan anticuerpos y el número de animales en riesgo de la población.

La prevalencia determinada se expresó con un intervalo de confianza (IC) del 95\% según la formula: $\mathrm{IC}=\mathrm{ZV}(\mathrm{pq} / \mathrm{n})$

donde:

$\mathrm{p}=$ prevalencia encontrada

$\mathrm{Z}=95 \%$ del nivel de confianza

$q=1-p$

$\mathrm{n}=$ tamaño muestral

Adicionalmente se determinó la asociación entre la variable dicotómica presencia de anticuerpos y las variables sexo, procedencia y actividad de los equinos sobre el total de los animales evaluados, haciendo uso de la prueba de regresión logística mediante el programa de análisis estadístico Statistical
Package for the Social Sciences (SPSS), versión 10.0 para Windows.

\section{Resultados}

La prevalencia del VHE-1 en la población de caballos fue de $44.2 \pm 4.6 \%$ (198/ 448). El VHE-1 tuvo mayor prevalencia en caballos dedicados a equitación, seguidos por los de carrera, y los caballos Peruanos de Paso (Cuadro 1). Los títulos de anticuerpos tuvieron un rango de $2 \mathrm{a}>256$. En el Cuadro 2 se muestra la distribución de los títulos de anticuerpos neutralizantes contra el virus según la procedencia y actividad de los animales. No se encontró diferencia estadística significativa $(\mathrm{P}>0.05)$ mediante la prueba de regresión logística entre la presencia de anticuerpos con las variables sexo, actividad y procedencia de los equinos.

Cuadro 1. Prevalencia del virus herpes equino tipo 1 en caballos según su procedencia, detectados por la prueba de neutralización viral. Lima, 2000-2001

\begin{tabular}{|c|c|c|c|}
\hline & \multirow{2}{*}{$\begin{array}{c}\text { Equinos } \\
\mathrm{N}^{\mathbf{0}}\end{array}$} & \multicolumn{2}{|c|}{ Positivo a anticuerpo contra VHE- } \\
\hline & & $\mathrm{N}^{\circ}$ & $\%$ \\
\hline \multicolumn{4}{|l|}{ A. Procedencia } \\
\hline - Pachacamac & 98 & 33 & 33.7 \\
\hline - Lurín & 18 & 6 & 33.3 \\
\hline - Cieneguilla & 42 & 16 & 38.1 \\
\hline - Surco & 174 & 82 & 47.1 \\
\hline - Chorrillos & 116 & 61 & 52.6 \\
\hline \multicolumn{4}{|l|}{ B. Actividad } \\
\hline - Caballo Peruano de Paso & 158 & 55 & 34.8 \\
\hline - Carrera & 174 & 82 & 47.1 \\
\hline - Equitación & 116 & 61 & 52.6 \\
\hline Total & 448 & 198 & 44.2 \\
\hline
\end{tabular}


Cuadro 2. Distribución de los títulos de anticuerpos neutralizantes contra el virus herpes equino tipo 1 en caballos reactores, según procedencia y actividad $(n=198)$. Lima, 2000-2001

\begin{tabular}{lrrrrrr}
\hline & \multicolumn{6}{c}{ Titulo de Anticuerpos $^{1}$} \\
\cline { 2 - 9 } & \multicolumn{2}{c}{$2-8$} & \multicolumn{2}{c}{$16-64$} & \multicolumn{2}{c}{$128->256$} \\
\cline { 2 - 9 } & \multicolumn{1}{c}{$\mathrm{N}^{\mathbf{0}}$} & $\%$ & $\mathrm{~N}^{\mathbf{0}}$ & $\%$ & $\mathrm{~N}^{\mathbf{0}}$ & $\%$ \\
\hline A. Procedencia & & & & & & \\
- Pachacamac & 29 & 14.65 & 4 & 2.02 & 0 & 0 \\
- Lurín & 6 & 3.03 & 0 & 0 & 0 & 0 \\
- Cieneguilla & 8 & 4.04 & 7 & 3.54 & 1 & 0.5 \\
- Surco & 41 & 20.71 & 34 & 17.17 & 7 & 3.54 \\
- Chorrillos & 44 & 22.22 & 16 & 8.08 & 1 & 0.5 \\
\hline B. Actividad & & & & & & \\
- Caballo Peruano de Paso & 43 & 21.72 & 11 & 5.56 & 1 & 0.5 \\
- Carrera & 41 & 20.71 & 34 & 17.17 & 7 & 3.54 \\
- Equitación & 44 & 22.22 & 16 & 8.08 & 1 & 0.5 \\
\hline Total & 128 & 64.65 & 61 & 30.81 & 9 & 4.54 \\
\hline
\end{tabular}

${ }^{1}$ Inversa de la dilución del suero

\section{Discusión}

El $44.2 \pm 4.6 \%$ de las muestras de suero de caballos adultos de apariencia normal, y dedicados a diferentes actividades, tuvieron anticuerpos contra el VHE-1. Esto significa que los animales muestreados fueron expuestos al virus en algún momento de sus vidas, tal vez en la etapa temprana, donde el virus ocasiona problemas de tipo respiratorio que usualmente terminan con la recuperación del animal, a menos que el proceso se complique con infecciones bacterianas secundarias.

Es ampliamente conocido que en infecciones herpéticas, todo animal infectado debe ser considerado como tal de por vida, ya que el virus puede persistir en estado de latencia en el ganglio trigémino y sistema linforeticular, como en el caso del VHE-1 (Kaashoek, 1995). Este virus puede reactivarse ante situaciones de estrés con o sin la presentación de enfermedad aguda o subclínica; y como consecuencia de estas reactivaciones el animal presenta anticuerpos neutralizantes.

No existe en la literatura información detallada sobre la frecuencia del VHE-1 en la población equina del país; sin embargo, se sabe que la prevalencia del virus fluctúa entre 50 a $100 \%$ en Chile y Brasil (Planas, 1974; Manzur et al., 1980; Fernández, 1988). Esta menor prevalencia (44.2\%) comparada con lo reportado en los países vecinos podría deberse a factores climáticos o a densidad de población, ya que el virus tiende a difundirse más eficazmente en climas fríos o en animales estresados (Gilkerson et al., 1999).

La reactivación y difusión del VHE1 en lugares con alta población equina son comunes y de importancia epidemiológica para la transmisión viral a caballos susceptibles (Van der Meulen et al., 2000). El animal responde con inmunidad humoral ante una infección respiratoria, pero a pesar de la presencia de anticuerpos neutralizantes el ani- 
mal puede reinfectarse, significando que la inmunidad humoral no protege totalmente de nuevas infecciones (Mumford et al., 1995; Wilson, 1997). Esto es posiblemente debido a que la inmunidad inicial dura entre tres a seis meses requiriendo múltiples infecciones o vacunaciones para adquirir una sólida inmunidad. Se reporta que el VHE-1, así como las vacunas contra este virus son pobres inductores de la proliferación de células $\mathrm{T}$, explicando en parte la inmunidad inicial de corta duración (Ellis et al., 1995).

En el análisis estadístico aplicado para asociar la presencia de anticuerpos con las variables sexo, actividad y procedencia de los caballos no se enontró diferencias significativas, indicando que las variables estudiadas no constituyen riesgo alguno para la presentación de la infección por el VHE-1 en nuestro medio. Sin embargo, el $52.6 \%$ de los caballos dedicados a la actividad deportiva de equitación y el $47.1 \%$ de los caballos de carrera presentaron anticuerpos contra el VHE-1 comparado al 34.8\% de los Caballos Peruanos de Paso (Cuadro 1). La mayor tendencia en la frecuencia del virus en animales de carrera y equitación puede deberse al estrés a que están sometidos estos animales debido a las prácticas de preparación física, contactos con nuevos animales, y frecuentes traumatismos, que podrían ocasionar inmunodepresión, favoreciendo las reactivaciones o nuevas infecciones virales (Allen et al., 1999).

La prueba de neutralización viral es la técnica estándar para el diagnóstico de la rinoneumonitis equina, con una especificidad diagnóstica cercana al $100 \%$, dependiendo del sistema indicador, pero con una menor sensibilidad. Es así que una muestra podría ser considerada positiva a anticuerpos a partir de la dilución 1:2 (OIE, 2000). El alto porcentaje de caballos con títulos de anticuerpos entre 1:2 a 1:8 podría indicar anticuerpos residuales producto de antiguas infecciones primarias, reactivaciones virales, o anticuerpos vacunales, pues la prueba de neutralización viral no discrimina anticuerpos de origen vacunal de los inducidos por virus de campo (Allen et al., 2000; Van Maanen et al., 2000).

Los 7 caballos adultos aparentemente sin historia de vacunación dedicados a la carrera y sin problemas respiratorios $\mathrm{ni}$ reproductivos mostraron títulos mayores a 1:128 (Cuadro 2). Sin duda, estos niveles de anticuerpos habrían sido producidos por infecciones subclínicas (Van Maanen et al., 2000). Una de las consecuencias de estas infecciones subclínicas es el aborto en las yeguas preñadas, donde llegan a presentar títulos mayores a 1:256 (Rivera et al., 1997); aunque se menciona que la importancia biológica de estos niveles elevados de anticuerpos respecto a la inmunoprotección es cuestionable (Burky et al., 1990).

Existen escasas informaciones en el país acerca del rol del VHE-1, sobre todo, en los animales jóvenes, pero la presencia de anticuerpos en el $44.2 \%$ de los caballos estudiados significa que la infección por este virus tiene amplia difusión en la población equina de Lima, especialmente en los caballos dedicados al deporte. Es posible que muchos de los problemas respiratorios, casos esporádi$\cos$ de encefalitis, y abortos puedan ser debidos a los virus herpes equino tipo 1 y 4 , pero que podrían estar siendo confundidos con otras infecciones, sobre todo cuando estos problemas no son diagnosticados con ayuda del laboratorio. Esta aparente falta de casuística en el laboratorio puede deberse a que las infecciones no son tan severas como en otros países, principalmente por el clima, pero también por la falta de comunicación del problema por parte del criador o propietario.

\section{Agradecimiento}

Los autores agradecen al personal del Laboratorio del SENASA, Ministerio de Agricultura, a la Dra. Lilian Fletcher, así como al Dr. Alejandro Montoya de la Escuela de Equitación de Caballos del Ejército Peruano de Chorrillos por proporcionar las muestras de suero de los caballos. 


\section{Literatura Citada}

1. Allen, G.; J. Kydd; J. Slater; K. Smith. 1999. Advances in understanding of the pathogenesis, epidemiology and immunological control of equine herpesvirus abortion. En: Wernery, U., Wade,J.F., Mumford J.A., Kaaden, O.R. (eds). Equine infectious diseases VIII, Proceedings. R\&W Publications. Dubai. p 129-146.

2. Allen, G.; J. Kydd; J. Slater; K. Smith. 2000. Equid herpesvirus 1 and 4 infections. En: Infectious of Livestock. Coetzer, J.A.W., Thomson, G.R. Tustin, R.C. (eds). Oxford University Press. Cape Town, South Africa.

3. Burky, F.; W. Rossmanith; N. Nowotny; C. Pallan; K. Mostl; H. Lussy. 1990. Viraemia and abortions are not prevented by two commercial equine herpesvirus- 1 vaccines after experimental challenge of horses. Vet. Q. 12: 80-86.

4. Ellis, J.; J. Bogdan; E. Kanara; P. Morley; M. Haines. 1995. Cellular and antibody responses to equine herpes viruses 1 and 4 following vaccination of horses with modified-live and inactivated viruses. J.A.V.M.A. 206: 823-832.

5. Fernandez, W. 1988. Determinacao da infeccao por Herpesvirus Equino tipo-1 en animais criados no Estado de Sao Paulo, a través da prova de fixacao do complemento. Tesis Maestria. Fac. Med. Veterinaria y Zootecnia. Univ. de Sao Paulo. 51 p.

6. Gilkerson, G.; J. Whalley; H. Drummer; M. Studdert; D. Love. 1999. Epidemiological studies of equine herpesvirus 1 (EHV-1) in thoroughbred foals: a review of studies conducted in the Hunter Valley of New South Wales between 1995 and 1997. Veterinary Microbiology 68: 15-25.

7. Kaashoek, M. 1995. Marker vaccines against bovine herpesvirus 1 Infection. $\mathrm{Ph}$ D. Thesis. Utrecht University. The Netherlands. $11 \mathrm{p}$.
8. Manzur, P.; P. Berrios; M. Celedón; L. Ibarra. 1980. Rinoneumonitis equina, estudio de niveles de anticuerpos seroneutralizantes en equinos fina sangre de carrera. Arch. Med. Vet. 12: 245-248.

9. Mumford. J.; D. Hannant; D. Jessett; T. O'Neill; K. Smith; E. Ostlund. 1995. Abortogenic and neurological disease caused by experimental infection with equid herpesvirus-1. En: H. Nakajima; W. Plowright (eds). Equine Infectious Diseases VII. Newmarket (Suffolk). R.W. Publishers. p 261-275.

10. Office International des Epizooties $(O I E)$. 2000. Equine Rhinopneumonitis. En: Manual of standards for diagnostic test and vaccines. $p$ 567-575.

11. Planas, A. 1974. Ensayo de la prueba de fijación del complemento en un estudio prospectivo de la rinoneumonitis equina en caballos fina sangre de carrera. Tesis Bachillerato. Fac. Cs. Pecuarias y Med. Veterinaria. Univ. de Chile. Santiago. $35 \mathrm{p}$.

12. Rivera, H.; H. Samamé; R. Oballe. 1975. Aislamiento y caracterización de un virus aislado de feto equino abortado. Rev. Vet. Zootec. 126: 10-13.

13. Rivera, H.; R. Alvitres; A. Manchego; N. Sandoval; R. Rosadio. 1997. Aborto por Virus Herpes Equino. Rev. Inv. Pec. IVITA (Perú) 8: 49-55.

14. Van der Meulen, K.; H. Nauwynck; W. Buddarert; M. Pensaert. 2000. Replication of equine herpesvirus type 1 in freshly isolated equine peripheral blood mononuclear cells and changes in susceptibility following mitogen stimulation. J. Gen. Virol. 81:21-25.

15. Van Maanen, C.; E. De Boer-Luijtze; C.Terpstra. 2000. Development and validation of monoclonal-antibody blocking ELISA for the detection of antibodies against both euine herpesvirus type 1 (EHV 1) and equine herpesvirus type 4 (EHV 4). Vet. Microbiol. 71: 37-51.

16. Wilson, W. 1997. Equine Herpesvirus 1 Myeloencephapopathy. Vet. Clin. North. Am. Equine Pract. 13: 53-72. 